\title{
Managing ambiguity: between markets and managerialism - a case study of 'middle' managers in further education
}

\section{Denis Gleeson and Farzana Shain}

\section{Abstract}

Advocates of devolved and market oriented Education reform, point to the benefits from self determination which enhance both teacher and managerial autonomy. Critics refer, on the other hand, to the ways in which running education institutions on business and accounting principles have introduced a new managerialism (Clarke et al, 1994; Pollitt, 1990; Clarke and Newman, 1997), which has driven a wedge between lecturers and senior manager interests. In Further Education, according to Elliott (1996a), this finds expression in conflict between lecturers in defence of professional and pedagogic values, and senior managers promoting the managerial bottom line (Randle and Brady, 1994). The danger in polarising such interests in this way is that it presents a plausible, if not oversimplified, analysis of organisational behaviour as market forces permeate FE. If this paper concurs with many critics on the effects of the new managerialism, it departs company from a prevailing determinism which assumes an over controlled view of the FE workplace (Seddon and Brown, 1997). Despite evidence of widespread casualisation and deprofessionalisation in FE, this paper examines changing managerial cultures in the FE workplace, in this case among academic 'middle' managers, which suggests that managerialism is not as complete or uncontested as is often portrayed. The paper draws on an ESRC research project conducted by the authors (ESRC no. R000236713), looking at Changing Teaching and Managerial Cultures in FE, at a time when the sector is emerging from a series of funding crises associated with redundancies, industrial action, mismanagement and low morale at college level.

\section{Introduction}

This paper critically examines the complex and contradictory role played by academic 'middle' managers, as mediators of change, in 108 Cowley Road, Oxford OX4 1JF, UK and 350 Main Street, Malden, MA 02148, USA. 
the reconstruction of professional and managerial cultures in the Further Education (FE) sector. With few notable exceptions (Ainley and Bailey, 1997), FE research has subsumed the experiences of lecturers and managers within a managerialist imperative (Elliott, 1966a and b; Elliott and Crossley, 1994; Randle and Brady, 1994; 1997), without sufficient attention paid to their narratives and experiences of the FE workplace.

In this paper we explore the role played by middle managers as an ideological 'buffer' between senior managers and lecturers through which market reform is filtered in the FE workplace. Drawing on an ongoing ESRC project, Changing Teaching and Managerial Cultures in FE (CTMC for short), the paper examines the often volatile working conditions in $\mathrm{FE}$, which give rise to ambiguity and connect lecturers and senior managers in a complex duality of control and support (Hetherington and Munro, 1997; Watson, 1997). In so doing, we consider the way such duality finds expression in the 'double' identities of middle managers, as they broker materiality and meaning in their work in this expanding $£ 3.5$ billion sector. We also connect this to the regulation and reconstruction of lecturers' work (Dale, 1989; Avis et al, 1996; Seddon, 1997), in the context of economic, political and cultural change in the FE workplace (Casey, 1995; Labier, 1986). The term 'middle manager' is employed to denote a diverse group commonly referred to within FE as 'middle management'. Specifically, within their various institutions, they are known by one of the following broad titles: programme manager, programme developer, co-ordinator, head of school, sector head or programme leader. Our use of the term 'middle' manager here, therefore, describes members of the FE workforce who assume managerial responsibility for the co-ordination of courses, people management, budgets and income generation, often having originally entered FE as classroom teachers.

\section{Background: the changing policy context}

The 1992 Further and Higher Education (FHE) Act granted FE institutions their independent corporate status. Colleges are now corporations governed by non-elected boards drawn mainly from business and industry. The Further Education Funding Council (FEFC) was initiated by Government with the task of ensuring the 'adequacy' and 'sufficiency' of provision in the sector. It assumed responsibility for Inspections previously performed by HMI, and 
for the funding and strategic control (though not curriculum) of colleges, previously the domain of the Local Education Authority (LEA) (McFarlane, 1992). Despite an increase in autonomy, FE colleges are in reality controlled by central government principally through the FEFC's funding mechanisms (Randle and Brady, 1997). The new funding formula, based on the principle of 'more for less', means that funds may be 'clawed back', if colleges fail to meet targets, retain students or if students do not successfully complete courses. The FEFC is, therefore, a crucial agency in the new management of FE in terms of funding, inspection and quality control.

These changes, however, cannot be attributed solely to the 1992 FHE Act; neither can they be seen as suddenly imposed. FE has historically operated in a voluntaristic fashion in the marketplace and centralisation has been a gradual process (Elliott, 1996b). The 1988 Educational Reform Act (ERA) initiated the process of removing the LEAs' control over School and Post Compulsory education. The incorporation and marketisation of FE soon followed on and cannot be understood without reference to wider educational reforms, including the sustained attack on public sector professionals from the late 1970s on (Avis et al, 1996).

In the immediate post war period the shortage of qualified teachers, the public demand for increased educational opportunity and the strength of organised labour placed teachers in a strong market position and permitted teachers to defend their licensed autonomy gained in an earlier period (Dale, 1989). In the 1950s and 60s these factors combined to strengthen claims for teacher autonomy and to force the state to maintain the rhetoric of indirect rule, partnership and professionalism. However, with economic contraction and growing political instability, teachers came under increasing attack (Grace, 1995). Following Labour's election defeat in 1979 the momentum was taken up by Thatcherism and the new right, with its emphasis on traditional values, market discipline and the doctrine of tight fiscal controls over public expenditure. It was also during this period that a new discourse of education workers had been constructed, sparked by the Ruskin speech of 1976. In this speech, the then Labour Prime Minister, James Callaghan, identified the teaching profession as complacent and failing to pay sufficient attention to skills and attitudes required to regain Britain's declining prosperity (Esland, 1996). Thus, by the time Margaret Thatcher's new right government had been elected, images of teachers as self serving and monopolistic were already being reworked in common sense, to justify greater state control and regulation of education (Ozga, 1995). 
Over the past two decades, in a period of recession and mass unemployment (Friend and Metcalf, 1982), this reassertion of control has been achieved through direct state intervention in education, while paradoxically leaving education to market forces. This 'free market/strong state' approach to crisis management (Gamble, 1988) finds expression in the 1988 Education Reform Act and the 1992 FHE Act. ERA introduced a series of measures which 'marketised' Education while simultaneously reclaiming central control through the National Curriculum and Assessment, thereby marking the end of teachers' relative autonomy (Dale, 1989). The Act introduced formula funding, Local management of schools and encouraged schools to obtain grant-maintained status, by 'opting out' of local authority control. This was further encouraged in the 1992 FHE Act, granting incorporated [independent] status to the FE sector. By privileging the market these reforms both realigned relations between teachers and the State and subjected teacher professionalism to externally imposed surveillance and funding control, thereby disconnecting teachers from any semblance of post-war consensus (Ranson, 1994).

Though focused on schools, ERA laid the framework for the incorporation of the FE sector, enshrined in the FE and FHE Act (1992). Financial and managerial control soon followed and were delegated to governing bodies of colleges in 1993. The Act also determined the composition of FE college governing bodies with a requirement of a minimum of 50 per cent business and industry representation, and a maximum of 20 per cent local authority representation (Elliott, 1996b). The FHE Act 1992, according to Gleeson (1996) created a framework of market competition in FE by:

- removing LEA control by transferring funding to the FEFC.

- completing the process begun by ERA, by granting FE and 6th Form Colleges independent status.

- introducing a competitive user-provider system linking colleges and student recruitment with TECs, Industry, Business and Commerce.

- initiating management systems which equated growth, units of resource and convergence, with lowering average levels of funding (ALFs); and by

- redistributing the subsidy from the supplier (colleges) to the customer (industry and commerce) and to the consumer (the student). (Evans, 1992).

Arising from this framework, education and training reforms, enacted by successive governments since 1979, have had two differ- 
ent but related objectives. Esland (1996) sees the first as economic in attempting to meet the demands from employers for a more vocationally relevant curriculum and assessment system, as part of the task of preparing young people for the flexible workforce of the 1980s and 1990s; the second, politically connected with the ambitions of the new Right, is concerned with the necessity to attack and replace the critical and liberal democratic basis of education, and to destroy its potential for undermining the free-market economy. Successive education reform in both schools and FHE has according to Esland (1996:48):

... substantially redrawn the lines of responsibility and accountability which have led to greatly increased regulation of professional workers and intensification of work loads. At the same time the introduction of a marketisation system of course provision and output related funding has heightened competitive relations between different institutions. (Esland, 1996)

Central to the processes of regulation and intensification is the discourse of managerialism (Clarke and Newman, 1997). This discourse has pervaded the new management of FE in an attempt to elicit the compliance of professionals in new modes of control over their work. It is to this aspect that we now turn.

\section{Managerialism and cultural change in the further education sector}

Ostensibly, managerialism has been introduced into education and the public sector as a rational process, linked with new principles of funding, efficiency and professionalism. A number of features of managerialism have been outlined in recent research (Pollitt, 1993; Fergusson, 1994; Clarke and Newman, 1997), which associate its economic rationalism with ulterior motives. These include, on the one hand, its control over professionals, by reasserting 'management's right to manage'. On the other, it conveys the notion that good management resides only in the private sector and by implication, that the public sector is characterised by liberalism and dogged sloth. This 'economising of education' brings with it the discipline of the market into the workplace, and the legitimising language that goes with it (Kenway, 1994). Through its discourse of Human Resources Management (HRM) and Total Quality Management (TQM), such 'economising' represents a powerful mechanism for both the internalisation of control, and surveillance of professionals 
in education and elsewhere in the public sector. Another controlling feature is the way in which managerialism turns senior professionals, who might be resistant to loss of professional autonomy, into managers. As Hoggett has argued:

... a new strategy of control [in the welfare state] is quite different to the previous bureaucratic one: rather than try and control professionals by managers, you convert professionals into managers (ie by giving them budgets or by setting them adrift as quasiautonomous business units. (Hoggett, cited in Avis, 1996: 109)

The process by which professionals can be reconstructed as managers of reform is of strategic importance to the implementation of market and managerial initiatives in education. Not only do academic managers play a crucial role in the manufacture of consent, between professional and managerial interests, but also their reading of situations closely mirrors changes in their own identities, which are as important as the reform process itself (Fergusson, 1994). Thus, contrary to an emphasis in recent FE research, which views professionalism and managerialism as opposed (Elliott, 1996; Randle and Brady, 1997), this paper examines connections between the two as they are mediated by changing identities in the work place. In this way we focus on the role academic managers play in constructing the meaning of FE, through their cultural activities at college level. As Senior Management Teams decrease in size as part of cost-cutting, and increasingly concern themselves with strategic planning, middle managers appointed from the lecturing ranks, are taking on broader managerial roles. They not only manage budgets and people in the pursuit of greater efficiency, but also mediate tensions and dilemmas associated with rapid and unpredictable change (Clarke and Newman, 1997). Among lecturers, reduced autonomy, insecurity, new contracts and longer hours, have further complicated the middle managers' remit. For senior managers budgetary deficits, pressure to attract more students and to compete with other providers, have sharply focused decision making in colleges. Moreover, preoccupation with corporate identity, mission statements and strategic planning have, according to Randle and Brady (1994; 1997), estranged many senior managers from their staff.

Such factors, accompanied by often grandiose refurbishment of college buildings, mirroring the new corporate image of FE, have signalled to many professionals working in FE its transformation from a public to a private sector of education (General Educator, 1997). In 
addition the language of FE has changed to reflect the new 'business' ethos, with students referred to as 'customers' or 'clients', teaching as 'the management of learning', and desks as 'work stations'. Combined, these factors have been significant in raising both the policy profile and the industrial relations temperature of FE. Perhaps the most significant aspect arising from such change has been the struggle over meaning and identity of professionals in the reconstruction of the FE workforce. To comprehend this involves recognition that FE is occupied by competing visions and cultures intimately connected with wider social and economic change. In short, there is a crisis of professional identity in FE which finds expression elsewhere in the public sector where fixed notions of professionalism, based upon a fragile post war consensus, are in question (Seddon, 1997; Ranson, 1994; Larson, 1990). Before going on to explore our preliminary findings a brief note on methodology is in order.

\section{A note on methodology}

Briefly summarised, the study focuses on the impact of government policy on FE (FHE Act, 1992), with particular reference to changing professional, teaching and managerial levels at college level. Through the perceptions of lecturers and managers the study analyses the way professionals interpret policy and practice changes in post incorporated colleges. As part of the CMTC project, fieldwork was conducted by the authors over an eighteen month period from January 1997 to March 1998, across five colleges in three counties in the Midlands region. In each institution, semi structured interviews were conducted with a cross section of twenty to twenty five individuals, including principals, governors, senior and middle managers, lecturers, support staff and union representatives. In all, over one hundred and fifty interviews took place which included some follow up individual and group interviews. In addition, documentary data (inspection reports, strategic plans, policy documents and internal memorandums), from the colleges was analysed and observations were recorded where possible of key meetings (strategic planning, management and sector meetings).

This paper draws mainly on accounts of thirty one (eighteen male and thirteen female) 'middle managers' (programme managers, teachers and developers, sector, school and faculty heads) across the five colleges involved in the project. Interviews with participants covered a range of questions regarding their role, position, experience and perceptions of their work about the ways in which national 
reforms impact on their work at college level. Though not specifically recorded here we also took cognisance of other participants' perceptions of how they saw middle managers in terms of their strategic importance at college level. The middle managers interviewed were drawn from a variety of backgrounds in terms of age, experience, responsibilities, gender and length of service. Though each institution was subject to different geographical educational, business and labour market conditions, we have sought to illuminate different narratives which express recurring themes among participants across the colleges. These are outlined in the section which follows under four sub headings: 'caught in the middle', 'managing ambiguity', 'the management of consent' and 'the fear of redundancy'. The research on which such an approach draws attempts to capture and analyse the professional work experiences of a small group of middle managers as they mediate FE reform at college level. In theoretical terms we have endeavoured to analyse such data in terms of the wider policy context outlined at the beginning of this paper, which connects managerialism with the identities and experiences of professionals 'on the ground'. Thus, any claims made for the authenticity of this study reside less in conventional notions of representativeness, and more in the qualitative complexities of analysing changing professional and managerial cultures in the fractured environment of the FE workplace. The section which follows takes further the notion of mediation among middle managers, to which we now turn.

\section{Mediating change}

\section{Caught in the middle}

Many of the middle managers interviewed spoke of being 'caught in between' senior management and lecturers. They also spoke of being at the sharp end of service delivery where both job and identity were being squeezed.

Mike: As a sector head now, as a part of Middle Management, I feel as though we are in danger of being squeezed and squeezed from the top and from underneath ... what has inevitably happened is that a lot of stuff [senior managers] would have been responsible for in days gone by, has come down to our level and I don't feel we have the opportunity to off load further down. 
In addition to the sense of being 'squeezed from the top and from underneath', there is also a perceived lack of support from senior management which presents its own problems. Consequently many middle managers feel they are being asked to perform an impossible task, without the necessary tools for the job. This at times has left them open to criticism from both senior managers and lecturers:

Chris: we have become the people who are linked very much with the staff, and get the blame from the staff and also unfortunately suffer the blame from the Senior Management Team for things we are not able to manage. Basically they are asking us to manage but tying our hands behind our backs. That is how I feel.

The sense of being squeezed in the middle relates not only to the experience of being 'caught between' senior managers and lecturers, but also in relation to the problem of balancing finance with curriculum issues, particularly where devolved budgets are in operation:

William: In another sense, we are in the middle because at our level of management we have got to balance the financial pressures which are coming down from Incorporation and the strict instructions to make sure that whatever we do, we do profitably, against providing what is a reasonable curriculum basket of provision for those people we come across. I think that is a difficult balancing act that we have to play because sometimes, if it was just the financial situation at stake, we would be looking at closing parts of the college.

\section{Managing ambiguity}

Another key concern relates to the ambiguous territory which middle managers occupy between lecturers and senior managers, and whose recognised identity as a 'manager' is not fully understood by lecturers or senior management, or even among middle managers themselves:

Jenny: The staff don't really know where we fit in and I don't think the senior management really know where either . . . I don't know where we fit.

Promoted from the ranks, many 'middle' managers retain often heavy teaching commitments and, at the same time, are expected to 
'hold the line' between lecturers and senior managers in brokering change. If their strategic influence is in mediating messages between senior managers and lecturers, they are in many ways more 'managed' than those who they allegedly manage (see Watson, 1997):

Bob: I see myself as a teacher, but the pressure from above is nothing to do with teaching. The pressure from above is always management related and it is usually urgent rather than important so I get kicked for something that is urgent, in my opinion at the expense of the important thing which is teaching. I don't know the answer, not when we are in such debt.

Ambiguity, in the form of being neither senior lecturer nor lecturer, allows middle managers some room for manoeuvre. However it can often be at a cost, particularly when financial pressures come to the fore. In this context middle managers are not victims or simply 'middlemen' but deal with complex moral and ethical decisions on a daily basis, often bounded by severe financial constraints. Though potentially flatter neo-Fordist work practices threaten their future, they effectively remain key intermediaries in potentially conflictual relations between professional and managerial interests. Evidence for this is to be found in the 'double identities' which middle managers account for in their work, and in their perceptions of themselves. These narratives relate both to their reading and identification with the new 'business' of Further Education, and their teacher based antipathy to trends or oppressive managerial fashions. This equivocal stance, referred to by Watson (1997) as a double control problem, shifts between a fascination for, and an ambivalence to, managerially driven reform. The nature of this duality of control which we call 'double identities' connects both with the communicative contingencies of the job and its meaning in middle managers' lives. It also marks a deeper realisation among them that they have been promoted, often from within, on the basis of their recognised skills in controlling rank and file peers.

\section{The management of consent - the translation of policy into practice}

In the narratives of middle managers it is strikingly noticeable how highly they regard achieving effective working relations with teachers and senior managers. On the one hand, this demands working closely with senior management in implementing often controver- 
sial policies and, on the other, it involves communicating and enlisting the co-operation of lecturers in carrying these out. Between both groups middle managers have the tricky task of constructing the art of the possible in translating policy into practice in ways which are acceptable and make sense to both groups. Their professional mandate is bound up with reducing potential conflict of interests and in minimising possible signs of a 'them and us' scenario. In this respect they filter change in both directions between senior management and lecturers, buffering potential conflict and resistance from lecturing staff.

Jenny: We act as a filter really, not only for the students but we also act as a filter for the staff and they will say things to us that they would never dream of saying to senior management; and they would hope that we would then pass that on.

A key function of the middle manager is then tied to the management of consent in work practices that operate within an environment of increasing public scrutiny and accountability, based on a principle of 'more for less'.

Chris: I feel I am a hard task master in that I expect my staff to work very hard. I don't expect people to be absent even though obviously people are genuinely absent. I expect a certain amount of commitment. I am expecting probably too much for what some of the staff are paid ... I can tell people off and I can make people work. It is not a question of making them; I can encourage them to work and they won't mess about because they know that as well as having strong foresight I am probably their own worst enemy. I could be, but I don't have to be . . . it is not my style to blow up at people and shout and bawl.

The task of policing potential conflict is not made easy by a tendency for teachers and senior managers to display polarised identities, in the defence of either pedagogy or in the promotion of management interests (Elliott, 1996a). In brokering such interests the language of becoming a 'good' academic manager displays all the tensions which link colleges with wider education policy, an issue to which we now turn. 
Facing the constant threat of redundancy and living with vulnerability

The growing culture of reorganisation, delayering or restructuring poses a threat to the life span of the FE middle manager. It also serves as a reminder to all staff in the FE organisation that they can be removed, or demoted in the interests of greater efficiency and economy. Although some middle managers were more willing to talk openly about this vulnerability than others, lecturers were in no doubt as to the increasing uncertainty and unpredictability that impacts on both lecturers and managers in the FE workplace:

\section{Mary: I don't think our Programme Managers have very much power at all. . . You are constantly in a culture of reorganization ... do not make too many waves because it's very easy to reorganise and you're out. So I don't think Programme managers stand up to the Principal in the way they should.}

The narratives considered so far underline a deepening industrial relations crisis in FE since Incorporation in 1993. With year on year savings of 6-9 per cent in college budgets many FE lecturers have experienced reductions in their pay, security, academic freedom and job satisfaction, accompanied by increases in their work load (Beckett, 1998). This coupled with widespread college insolvency, sporadic strike action and financial mismanagement, has in a short period, turned FE into an industrial relations battlefield. For those in posts prior to Incorporation the combination of efficiency gains and restructuring has had a marked effect on morale and career prospects.

Bob: After incorporation there was a restructuring and Heads of Division were no longer going to exist. I was then a senior lecturer and I was either going to be made redundant or I had got to apply for a Development Manager's role and I applied for the Curriculum Manager's job which I got. I did that for a couple of years and there was another restructuring... so we then had to apply for jobs again. There was only one set of Development Managers' jobs and neither ... myself or the other internal applicant got the job. I was given a Programme Manager's job which was a demotion I guess ... Now I have got a programme area that is about twice the size as it was this time last year, and with a pay decrease. 
Elsewhere, Beth refers to her worries about redundancy and what may happen to her:

Beth: ... I worry that if I was made redundant, how would I survive? What would happen to me? I think there is always that fear and that is a possibility if we didn't get the student numbers, so perhaps that is what drives the concern and care that comes out in this department.

Even those middle managers who had recently received promotion felt vulnerable. Bill, one of the most ambitious and well paid managers interviewed also expressed such vulnerability, despite his apparent success on the career ladder.

Bill: Don't even ask me the question because it makes me feel even more vulnerable. Personally speaking, I feel extremely vulnerable. The main reason for that is I am quite highly paid as a college manager. My job could be done by somebody younger who would have a lower salary than me.

A number of further questions arise from such accounts, as to how middle managers resolve such ambiguity and vulnerability in the work place. It is, for example, too simplistic to view middle managers as either 'puppets' or 'free agents' in their dealings with the sharp end of user-provider reforms in education or elsewhere. At the same time middle managers are neither victims or 'honest brokers', but have to deal with complex moral, administrative and pragmatic decisions on a daily basis, often bound by severe financial constraints. Though restructuring and delayering practices threaten their future, they remain effectively key intermediaries in potentially conflictual relations between professional and managerial interests. Despite their ambivalence about being 'caught in the middle' of budgetary, staffing and management constraints, many middle managers view their new responsibilities positively. Those whose established middle tier posts (for example, as heads of department or subject leaders) became subsumed in wider management reforms, or who had promotion thrust upon them (following early retirements and redundancies), often tend to view the job more instrumentally and individualistically. However, middle managers do not constitute a neat homogenous group. Their responses to, and perceptions of, their work varies in relation to institutional effects, age, gender, qualifications and work experience, none of which alone 
tells the full story. In the section which follows, we seek to make further sense of our data by developing a heuristic model for analysing narratives around recurring responses of compliance: willing, unwilling and strategic. These are not intended to be exhaustive or fixed but to illuminate how different cultural responses arise from commonly experienced conditions of ambiguity and vulnerability identified by managers in the FE workplace. Here, we adopt a broadly vignette approach (Finch, 1987) drawing on recurring themes identified by participants in the study.

\section{Manager responses to change}

\section{Willing compliance}

Willing compliance is characterised by the expression of a deep commitment to the FE institution and its corporate image. Managers frequently used the terms 'we', 'us' or 'our' to communicate their individual identification with the college. Willing compliers are typically ambitious and have either been recently promoted, or are seeking promotion within the organisation. Often they are pursuing further management qualifications, most notably MBAs, to aid their promotion prospects. Although a minority retain direct contact with students, either through teaching or tutorial work, the majority have moved into management roles precluding their direct contact with students. A defining feature of this response is a conscious alliance with the corporate aims of the institution in line with the new managerialist work ethic of FE. This involves immersion in a discourse of 'business speak', with middle managers making frequent references to efficiency and effectiveness, and referring to students as customers or clients. According to Monica for example:

A successful college is one that satisfies our customers and I think we do ... it is one that encourages its customers to come back, and its customers to bring their friends.

The dominant managerialist discourse is consciously internalised and guides the daily working practices of those involved. Incorporation is thus spoken of in both positive and realistic terms as offering the only possibility of strategic direction and change in the changing business climate of FE. Changes in the corporate appearance of the college are also cited approvingly as indicative of a new professional era. In such accounts 'professional' is used synonymously as a noun 
or adjective that is uncoupled semantically from profession to denote the business of FE in terms of efficiency, reliability, compliance and a no-nonsense anti-intellectualism (Ainley and Bailey, 1997). In this discourse of professionalism, skill is given priority over knowledge and compliance over judgement - essentially being a professional is associated more with a predetermined product and brand image, than with pedagogy and studentship (Hoyle, 1995).

Monica: This college has had to wake up. It has had to realise that nobody will bail it out if it goes under. It has had to develop a professional air which in some areas they [lecturers] still don't have; they still have the view [that] 'I am the teacher and the student must put up with it'. In the main there is a growing feeling of professionalism. Now we are front of house. We look as smart as we can. We attempt to be as professional to our public as we can. We have a frontage ... We have had to set up a new personnel office and a new finance office, whereas we relied on the LEA before.

Middle managers such as Monica view flexibility and working long hours positively in exchange for possible recognition and promotion. The constant and rapid change referred to so far, though a source of fear and frustration to many managers, is viewed as positive, challenging and exciting by willingly compliant managers.

Karen: I am very interested in change and I am one of those awful people who have to keep moving. I like challenges and so I find this restructuring is very exciting. It's the best thing since sliced bread in my point of view.

Such compulsive optimism about organisational change, and one's role within it, is congruent with Casey's colluded self (Casey, 1995), where the strategy is used as a psychic buffer to filter competing messages and impulses. Following the corporate line provides some managers with a modern focus on which to build their professional identity. Key phrases from mission statements are often internalised and reproduced in the interview situation. This adoption of the corporate line also involves close identification with senior managers' assessment of the new found freedoms that go with incorporation. In line with the corporation's official views, competition between colleges is viewed as healthy, with some managers speaking of being 
'bled dry' by colleagues from other colleges. As Karen put it, 'These people are our competitors'. Resultant changes in the conditions of teachers' work, which have also significantly impacted on managers, are viewed as inevitable and necessary for the overall efficiency of the system

Monica: A teacher is expensive. It is easier to have one teacher and five classrooms by having it beamed in on the television than have a teacher in every room, but ... that has got to be balanced I think.

Another associated characteristic of willing compliance finds expression in the corporate style of dress adopted by some managers. Suits in neutral and safe colours (navy and grey) are often worn by both men and women middle managers in preference to smart casual gear. Bill made a conscious decision to change his style of dress as he worked his way up what he terms 'the greasy pole of management'. Having started his working life as a lecturer and union member he describes the way in which he consciously altered his physical image (cutting his hair and wearing suits), in order to become a 'company man', identifying strongly with the corporation.

FS: You describe quite a few changes since the 1988 Reform Act leading to Incorporation. What has all that meant for you?

Bill: Personally? That is a very difficult question to answer because I am such a company man now. I suppose, at one time I had a very strong Trade Union background and I used to be NATFHE Secretary ... I had quite a different kind of perspective then ... It is only recently in the last couple of years I have taken an MBA in trying to look very carefully at financial and administration aspects of handling colleges. I suppose now because my role of the past years has been very much outside any departmental struggles if you like, I do tend to have a fairly broad view. I think of what colleges are all about.

FS: So how have you adjusted to that sort of change from being 'radical and wanting to change the world' to becoming this 'company man'?

Bill: I think the adjustment came in 1974 when I opened a Burton's account and took off my jeans and took off my Reeboks and leather jacket and started wearing a suit and cut my hair. 
Significantly, a majority of those middle managers interviewed in this category are women. The emerging less male-orientated culture of $\mathrm{FE}$ is seen by them to offer new opportunities in exchange for long hours of service and total dedication to the organisation. This contrasts with, or perhaps complements, research emphasising the 'macho' culture of management in FE (Kerfoot and Whitehead, 1998). As a consequence work and out-of-work life becomes increasingly difficult to separate; and the tariff for such ambition is self-exploitation of women managers' 'feminine selves'. Female middle managers find the prospect of promotion a challenge that bonds them to the organisation but which, at the same time, trades on their womanly skills and ambitions (Casey, 1995):

Monica: I can't let go, that is the problem. It is so exciting, I can't let go and it is to my detriment in a way. I know it is not doing me any good but it is how to get promotion. I haven't yet solved the problem. I also am still looking for promotion.

In the process of seeking promotion, female middle managers find themselves at the sharp end of service delivery, managing and resolving tensions in the workplace resulting from budget cuts and contraction in resources and services. They work long hours to cover staff shortages and resultant conflicts which surface amid a climate of cut-throat competition. Karen, for example, described to us a 'communication' problem that existed between colleagues in her department, as a result of which Karen's own workload increased. She views this as a necessary part of her role, in order to maintain what she perceives as a 'happy atmosphere' in her sector:

Karen: ... it's a very flexible role but maybe I make it too flexible. People tell me I'm a fool because I am exposing myself. I am there all the time but I think we have quite a family atmosphere in our area. Our classrooms are on one corridor so we share access and notice boards. We can put up and share all the work.

Willing compliers express commitment to the college, frequently referring to meetings and conversations with Principals or senior managers, who are referred to by first name. Karen identifies strongly with her new Principal whom she regards as 'dynamic'. She is also of the same age as the Principal and believes that the 
Principal 'values experience over youth'. She therefore talks positively and optimistically of the future and of her own place within it.

Karen: I see the future of this college being very successful. We have got a very dynamic Principal here. She has a lot of ideas. She has got a finger in every national forum that we know. She is highly motivated and has got lots of energy and if she sees a business part falling, she will pick up somewhere else ... So I see the future here as very exciting, I think people who perhaps haven't worked so hard will have to pull their weight and people will be accountable. I think that is not a bad thing.

Elsewhere, Patricia's compulsive optimism - linked with a positive sense of family - represents a strong antidote to the perceived pressures involved in her work.

\section{Patricia: . . . I feel a deep commitment to the college on many levels. As a parent, as a member of the community and as a member of staff as well. I do feel optimistic about it. I think the college is under threat but the staff have a real commitment to it.}

Despite expressing such high levels of commitment to the organisation, few middle managers felt able to escape totally from the vulnerability that is an essential part of their new corporate life. Not all our respondents were willing to speak as openly about this vulnerability as Bill, cited earlier, and Monica:

\section{Monica: ... I do fear redundancy and seeing what has happened at our college, anything can happen, absolutely any- thing. So I don't feel that I have security of tenure at all ... Nothing is certain, but one of the things I think is important, is to keep developing yourself . . . that is what I have always done, and I have enjoyed it.}

Monica also detects gender discrimination in the way the organisation operates, which makes her feel uncertain about her position in the institution, and hence extremely vulnerable:

The college has just appointed a new Director and he is in the Senior Management Team, but is also called Director. I am a 
director and so is Beth but we are not in the Senior Management Team, so I think that has got to be cleared up ... I don't know what level I'm on. My line manager tells me I am 'higher up' than heads of Sector. I know from the pay structure that I am not. I haven't got any actual evidence but I believe I am probably one of the more lower paid of all of them. I want to know where I stand really.

When asked further about her feelings of discrimination Monica felt this had much to do with the previous college regime.

Monica: I put it down to the views of the previous Principal, who in my view did not particularly want to promote women. I always felt at team meetings I was invisible. If I said anything it was always, 'Oh is she going to be long?' Whereas if any of the guys said anything it was, 'that's a really good point'. The Principal would say 'Come on you chaps'. The gender was always male and the words were [too] . . . so I was pleased when we appointed a new woman Principal. She is very good but I still feel marginalised and irritated because I have done a lot of good work and I never felt any recognition for it.

\section{Unwilling compliance}

If a characteristic of willing compliers is their level of interest and optimism in the organisation, the 'unwilling complier' is altogether more sceptical and disenchanted with the new FE ethos. Paradoxically, those values and challenges which most excite the willing compliers are those which unwilling compliers find most difficulty in relating to. Anger and frustration with one's lot is discernible, across the age, gender, qualifications and range of experience. It is a response which shares much in common with Casey's 'defensive self' (Casey, 1995), among those who have moved sideways, become stuck or who have been passed over for promotion - though not exclusively so. For younger managers like Andrew, recently recruited from industry, the college is not perceived to be 'business like' enough. Though he accepts the new corporate image of FE, he believes the college is not responsive enough to new 'business' principles. Following a number of suggestions rejected by senior management about how to improve things, he has become bitter and resentful of the work culture in his college. $\mathrm{He}$ 
has become frustrated by the lack of support received from senior management, which affects his ability to respond to what he terms elsewhere as the 'cut throat' nature of his work.

Andrew: It is the college mentality ... I have worked in business and the college wants to be a business but the college is miles off being a business. It would never survive if it was an industry ... the only business mentality that seems to come across is when something is going well ... but the people above you take credit for it. If something is going bad the buck stops with you, down at the bottom. 'Oh it's his fault; or it's not my fault I told him it would go wrong'. The load is so high you just can't cope with it anymore and you blow your top and then calm back down again, and a few weeks down the line you will be blowing your top again. . . . It is not a very good environment to work in; I don't relish coming to work in the morning.

FS: What actually brings you into work then?

Andrew: The pay cheque at the end of the month.

FS: A blunt answer.

Andrew: It's the truth. I don't think anybody works for anything bar the money nowadays.

For more experienced academic managers like Martin, unwilling compliance can result from the experience of demotion of some sort within the organisation. Delayering and restructuring often means that middle managers face the prospect of redundancy or applying for their own or redesignated posts. This can be accompanied by a reduction in status and pay, as in Martin's case, often with an enlarged responsibility:

Martin: I feel quite resentful to be honest. I had no choice about whether to apply for the job. It was that or run the risk of redundancy.

Since being 'reappointed' Martin has found it difficult to reconcile the loss of professional autonomy and status that had originally attracted him to FE. His despair is evident as he talks of the way in which senior management and the control mechanisms operate, in order to elicit compliance with new working arrangements.

Martin: I think we are much more at the mercy of senior managers now than we used to be. They can make us do 
almost whatever they want to. We have seen that for instance recently in the way people's work rooms have been chopped and changed as deemed appropriate.... Also ... we have had thrown at us the threat of redundancy which is a sort of macho management strategy to show us who the bosses really were with a new senior management coming in ...

He also spoke of what he saw as the callous way in which professionals were being treated in FE institutions. Despite feeling used and abused by the organisation, Martin complained that he had little option but to remain within his college. However, like Andrew he did not relish the thought of arriving at work each morning:

Martin: I think there has been over a number of years a sense of being used really. There are very few promotion prospects, not only within the college but the chance of moving to other colleges is quite remote. I think that people need to have a sense that if they work hard enough they will get some sort of recognition either through promotional prospects or through increased salary ... or being treated properly by their managers. At the same time as people were being threatened with redundancy they were asked to work harder by volunteering to give time to marketing events, or they were being asked to identify their holidays for next year. Some of them weren't even going to have jobs next year in theory and it seemed a rather callous way of approaching people. So I think that they should be treated properly as professional people.

FS: What then brings you into work?

Martin: I have to pay the bills. I would walk away tomorrow if I could find something else to do. I don't like saying that but it is the case and the problem is that I don't think there is anything else for me ... I don't go to work with a song in my heart. I go because I have to go and certainly last half term I was experiencing quite a number of physical symptoms of stress.

In Hayley's case, who experienced a loss of professional and financial status (due to job reallocation), bitterness and resentment is aimed at the system rather than the college. She has found it difficult to overcome the financial loss which she has experienced in and out of work, in both her professional and personal life: 
Hayley: . . . How was I going to live, after my salary was cut by nearly half from $£ 20,000$ a year. How was I going suddenly to continue with my mortgage, look after my children, pay my bills? . . . I felt very very angry towards the system and I still feel very very angry. I have to talk a lot about it. I talk to my husband who is not a teacher and thank goodness, I suppose in this respect that he isn't a teacher, he will listen ... whereas I think if maybe he was a teacher he would say, 'I have got enough stress in my own job'. So he listens and my friends listen.

If Hayley's case is not typical of those interviewed, the perceived threat of redundancy or job reallocation was uppermost in many lecturers' and managers' accounts. While there is no evidence in the CTMC study that willing compliers are any more or less advantaged than unwilling compliers in the job market, both groups are vulnerable in not possessing strategies for reconciling work and non work tensions. In different ways both display individualised and marginalised accounts of their relationship with work and non work situations. By contrast the 'strategic complier' often displays a strategic 'reading' and interpretation of change to their own and the organisation's advantage.

\section{Strategic compliance}

The vast majority of middle managers interviewed in the CTMC project complied strategically. This response is perhaps best explained as a form of artful pragmatism which reconciles professional and managerial interests. In their study of a Technical and Further Education (TAFE) college in Australia, Seddon and Brown (1997) describe such strategic compliers as possessing innovative strategies for dealing with the pressures of income generation, flexibilisation and work intensification while, at the same time, continuing their commitments to educational or other professional values of student care, support and collegiality. In the CTMC study, strategic compliers also retain their professional values and bend with change in order to protect their staff. Although they accept some aspects of the new FE work culture as non-negotiable (for example, new contract conditions) they attempt to work around these conditions within their own sectors, in different ways. They also maintain a strong sense of student and staff perspective, although variations exist in the approaches adopted by strategic managers. Some are 
beginning to get caught up in the competitive environment following the logic of economic rationalism so far described. For example, Ken believes that it is logical to close down certain sections of the college because they are inefficient. However, he speaks of his determination to protect staff from administration in order that they may get on with the job of teaching:

Ken: I think my job is to protect lecturers and the Heads of Section from the administration. They should just do the teaching and they should not be distracted from that. So it is easier if I do all the shit work basically and they concentrate on teaching.

Unlike willing compliers, middle managers such as Ken do not identify strongly with the corporate image of their respective institutions. They recognise that a major part of their role involves 'selling' the party line to lecturers as crisis and stress are pushed further down the line (Watkins, 1993). At the same time they also maintain a personal and professional distance from senior management, in order to retain their credibility with their staff. In doing so they manage and maintain context specific identities in their routine practices at work.

Chris: We have been told that we are managers. As a result we do protect the college as much as maybe the senior managers might do. You don't speak ill of the college. I feel we are very positive. I hope I'm not seen by my staff as too closely linked to senior management because that would not do my credibility any good, and yet I regularly have to put their line across to the staff, because my hands are tied.

Strategic compliers do not readily accept the 'party line' on definitions of quality as measured by output, or of professionalism as predetermined by service delivery. Although they comply strategically by switching identities in different contexts, they are also conscious of being consumed by managerial preoccupations and paperwork:

Isabel: I fear I could be removed totally from the person that I originally was. I don't particularly want that as it would turn me into 'paper woman' ... I think the culture is now 
that everybody is trying to prove that they deserve their job ... and one of the physical manifestations of the job is proving to have a pile of paper coming through as a task for somebody ... and that is almost at every level.

For Isabel real quality is defined in terms of a 'no frills' model, that is distinct from what she calls 'paper' quality:

Isabel: . . . [I believe in] . . the 'Kwik save model' of education, so that there are no frills; no frills so that you don't sink up to your belly button in carpet as soon as you come into the place or there is a razzmatazz lounge for the students to lounge around in . . . because I think ultimately the resources should go into materials and teaching. If you could just have this potent bit of teaching up front instead of all this other ... I am trying to keep my language here; all the other things muddy it . . . because students say, 'we don't care about the reception, we don't care about what is happening in the studios' . . What I would term as quality is the time for focus groups, where lecturers can get together and talk about non administration issues, but there is very little time. I have set up one or two meetings, a sort of rota of meetings, where I call them forums where we just talk; administration is banned and we talk about an idea or a concept.

In this case such meetings are sometimes held without the knowledge of senior managers. For middle managers such meetings are seen as essential for retaining some measure of professional autonomy based around educational values. In Chris's college, middle managers attempted to meet as a separate group in order to develop innovative strategies to deal with pressures of work intensification and income generation. Paradoxically, such action posed a threat to the dominant managerial culture of the college and was swiftly halted by the Principal.

Chris: I brought together the Sector heads' rogue meetings. The Principal said we couldn't meet. He didn't want an offshoot that was seen to be against the college. He misunderstood the reason why we met; we met to share ideas and most of the time to develop the college ... and not bitch at each other because some of us have got more 
students ... to try and see each other's point of view. The Principal didn't want that ... he found out about it. We didn't make it a massive secret because we didn't know he would object to it. We looked at various systems in the college to see what we required of them ... and what we required, on a regular basis, were certain things from Finance.

While this group drew on residual elements of professional and collegial culture in embracing the business culture of FE they were, at the same time, reminded of where power lies in the new corporate structure. Paradoxically their innovative 'reading' of how best to broker market and professional concerns in the interests of the college reveals conflict with senior management over how this is best achieved. Thus, if at one level middle managers are becoming more skilful at handling tasks which senior managers throw at them such actions - as those of the Principal - reinforce the ambiguity of their occupational role. However, without access to the necessary financial and other data middle managers have become adept at 'reading' signs and signals which connect the top to the bottom of the organisation, a factor often more important than the financial detail itself. Having an ear close to both senior managers and lecturers allows middle managers to interpret the 'middle ground' while, at the same time, maintaining distance between both groups allowing room for manoeuvre. Walter, for example, prefers to identify himself as a third layer of management, not part of the lecturing staff or senior management, but near to both; though significantly with roots in teaching.

Walter: ... I am not basically a through and through manager ... if you notice the 1970s heroes in programmes like The Sweeney, the hero is third level of management. Reagan wasn't a constable . . . he was a sort of middle manager shat on from above by Haskins, but a manager nevertheless in the thick of it. I actually enjoy this role. I enjoy being able to generate new projects but still nevertheless be near to the staff. I mean not part of the staff but near to them, able to share in what goes on and see things from their point of view ... and to promote teaching and learning ... I am a manager, oh yes, but it is a role I have grown into ... We are managers, we accept that now, but I think our roots are in teaching and I think we can't forget that, at least I don't and I still think that is probably what I do best. 
Unlike willing or unwilling compliers, such middle managers demonstrate a broader interpretation of their work, which is less defensive, optimistic and obsessive. In the context of the CTMC study, the different responses referred to signify the complexities of similar groups culturally interpreting the (FE) workplace in different ways. As Seddon and Brown (1997) note, decentralisation and marketisation drive diverse responses, shifting the patterns of education provision and practice in ways which are often double edged:

Neither advocates nor critics of reform, capture this complexity sufficiently. Each group is quick to flag either the good or the bad, the black or the white, in reform without acknowledging that the contemporary changes in education bring both good and the bad together in uncomfortable, and often confusing ways. Exciting developments in the application of technology in pedagogy and innovative assessment practices exist alongside and because of huge intensification, casualisation and the erosion of teachers' working conditions. (Seddon and Brown, 1997; emphasis in original)

Thus, to draw attention simply to the processes of deprofessionalisation without reference to its relationship to the processes of professional reconstruction is to misrecognise ways in which narrative and context give 'voice' to new reworkings of identity and professionalisation in the education workplace. However, focusing primarily on the effects of deprofessionalisation is reactive and implies that education is driven by external forces and that education workers are just victims of history (Seddon, 1997). While it is certainly the case that ongoing battles involving public sector workers (teachers, nurses, health, social workers and others) are being accommodated through managerialist principles, the process is by no means complete, uncontested or static. To see middle managers, therefore, as either fully fledged members of the corporation, as victims or malcontents, is to ignore how different cultures and identities are formed within and by changing work practices and, importantly, how they also influence those practices.

This brings us full circle to the central theme of the paper. If at one level, market and managerial reform in FE is seen to have undermined professionalism and collegiality, at another, it has paradoxically exposed anomalies and myths surrounding the very existence of such values. That being the case what new constructions of professionalism are emerging from a system acknowledged by many to be 
in crisis? If there was no 'golden age' of FE how are we to make sense of what is happening now? In addressing these questions we seek to provide a synthesis of some of the theoretical and substantive issues raised in the paper, as they bear on changing professional and managerial cultures in the wider context of education reform.

\section{Conclusion}

This paper has examined the role that middle managers play in the process of filtering market reform in the post-incorporated further education sector. In a climate of rapid and unpredictable change, in which struggles over the meaning, identity and ethos of FE have been to the fore, we have argued that middle managers play a crucial role in mediating change in the education workplace. In doing so, they are actively involved in the reconstruction of professional and managerial cultures in this volatile sector. Not only do they mediate different tensions between, for example, funding and curriculum, but they also filter competing messages from 'above and below', in the translation of policy into practice, effectively 'buffering' potential conflict between senior managers and lecturers. The dilemmas that middle managers face possess a materiality and meaning which cannot be disassociated from the interventionist role of the state. The accounts to which we have referred articulate the contradictions experienced by professionals in mediating tensions over funding, contracts and working conditions, which find their expression in a managerial state (Clarke and Newman, 1997), and in the identities of those who work for it. In the attempt to steer the economy to international competitiveness, education policy has shifted its corporate responsibilities onto individuals and institutions. Thus, in transferring the burden of bureaucracy and financial accountability onto schools and colleges, such institutions have become 'liable' for their own autonomy. However, in order to accomplish this steering role the contracting state has shrunk the public sector, making institutions self managerial in the process. Though obscured, the economic rationalism which underpins this process of control reveals itself in democratic forms associated with devolution and de-regulation. At the same time this process transfers responsibility for policy effectiveness and, in particular policy failure, from government to institutions themselves.

What we have sought to demonstrate are the ways in which such transference of power and control finds expression among 
professionals in the education workplace. However, the ambiguous territory occupied by middle managers in their various institutions is compounded by a vulnerability that gives rise to different professional responses within and across the loose categories of 'middleness' and 'duality'. Though there is some evidence of managers being incorporated into the dominant managerialist discourse of professionalism (that emphasises loyalty to organisations above collegiality; competence over knowledge, compliance over judgement and outcome over process), this is by no means complete. A majority of middle managers in this study, for example, adopted an approach of strategic compliance in dealing with pressures from above and below while, at the same time, maintaining a commitment to educational and other professional values in support of student care and collegiality. In maintaining a personal and professional distance from 'the corporation' they thereby managed and adopted context specific identities in their routine practices at work. By drawing on residual elements of public sector professionalism and reworking these values within the context of an incorporated and marketised model of FE, strategic compliers present a challenge to managerialism suggesting that professionalism is not a fixed or static concept but is rather subject to social, political and cultural definition. One interpretation of such mediation is to view it as an artful form of self preservation, in response to potentially conflictual relations between lecturer and senior manager interests. Another possibility is to see it as a basis for rethinking professionalism in the FE sector and for raising new questions about the way in which professionalism can be reworked and pursued in preferred ways (Grace, 1995; Seddon, 1997).

If a combination of market and managerialist policies currently restrict the possibilities of professionals seeking common purpose, they also draw attention to ways in which this can happen. Paradoxically, the limitations of devolved managerialism both negate and draw attention to the conditions which give rise to a variety of professional responses in the education workplace. As we have sought to demonstrate, the majority of middle managers in this study operated strategically to ensure that their staff were protected and that educational values were promoted as far as possible within the new management culture of FE. We would conclude by arguing that the accounts of middle managers discussed here say much about two things: first, they point to the ways in which new professional identities arise from ambiguities and contradictions in the education work place; and, second, they show how a variety of identities and responses, though shaped and influenced by manage- 
rialism, are not determined by it. This suggests that managerialism is not as complete or uncontested as is often assumed, and that we should look for innovative signs of professional life in new ways and places.

Keele University

Received 8 June 1998

Finally accepted 5 November 1998

\section{Acknowledgements}

The authors wish to acknowledge the support of the Economic and Social Research Council in funding the research on which this paper is based (ESRC award number R000236713). We are grateful to the staff in our case study colleges who took part in the research and were extremely generous in giving their time. Thanks are also due to two anonymous referees who commented on an earlier version of this paper.

\section{References}

Ainley and Bailey, (1997), The Business of Learning, London: Cassell.

Avis, J., (1996), 'The Enemy Within: Quality and Managerialism in Education', in Avis et al, Knowledge and Nationhood, London: Cassell.

Avis, J., Bloomer, M., Esland, G., Gleeson, D. and Hodkinson, P., (1996), Knowledge and Nationhood, London: Cassell.

Ball, S., (1994), Education Reform: A Critical and Post-Structural Approach, Buckingham: Open University Press.

Beckett, F., (1998), 'A Chance to Build Peace', Guardian Education, 20.1.98.

Casey, C., (1995), Work, Self and Society: After Industrialism, London: Routledge.

Clarke, J. and Newman, J., (1997), The Managerial State, London: Sage.

Dale, R., (1989), The State and Education Policy, Milton Keynes: Open University.

Elliott, G., (1996a), 'Educational Management and the Crisis of Reform in Further Education', Journal of Education and Training, 48 (1): 5-23.

Elliott, G., (1996b), Crisis and Change in Vocational Education and Training, Jessica Kingsley.

Elliott, G. and Crossley, M., (1994), 'Qualitative Research, Educational Management and the Incorporation of the Further Education Sector', Educational Management and Administration, 22 (3): 188-97.

Esland, G., (1996), 'Education, Training and Nation-State Capitalism: Britain's Failing Strategy', in Avis et al, Knowledge and Nationhood, London: Cassell.

Evans, B., (1992), The Politics of the Training Market: From Manpower Services Commission to Training and Enterprise Councils, London: Routledge.

FEFC, (1997), Annual Report, London: FEFC.

Fergusson, R., (1994), 'Managing Education', in J. Clarke, A. Cochrane and E. McLaughlin (eds), Managing Social Policy, London: Sage.

Finch, J., (1987), 'Research Note - the vignette technique in survey research', Sociology, 21 (1): 105-14.

Friend, A. and Metcalf, A., (1992), Slump City: the Politics of Mass Unemployment, London: Pluto. 
Gamble, A., (1988), The Free Economy and the Strong State; The Politics of Thatcherism, Basingstoke: Macmillan Education.

General Educator, (1997), Journal of the NATFHE General Education Section, Sheffield: NATFHE.

Gleeson, D., (1996), 'Post-Compulsory Education in a Post-industrial and Post-modern Age', in Avis et al, Knowledge and Nationhood, London: Cassell.

Grace, G., (1995), School Leadership: Beyond Educational Management, London: Falmer Press.

Hartley, D., (1995), 'The Evaluative State and Self-Management in Education: Cause for Reflection?', in J. Smyth (ed.), A Socially Critical View of the Self-Managing School, London: The Falmer Press.

Hargreaves, A., (1994), Changing Teachers, Changing Times, London: Cassell.

Hetherington, K. and Munro, R., (1997), Ideas of Difference: Stability, Social Spaces and the Labour of Division, Oxford: Blackwell Publishers.

Hoyle, E., (1995), 'Changing Conceptions of a Profession', in H. Busher and R. Saran (eds), Managing Teachers and Professionals in Schools, London: Kogan Page.

Kennedy, H., (1997), Learning Works: Widening Participation in FE, Coventry: FEFC.

Kenway, J., (1994), (ed.), Economising Education: The Post-Fordist Directions, Deakin University: Deakin University Press.

Labier, D., (1986), Modern Madness: The Hidden Link between Work and Emotional Conflict, New York: Simon and Schuster.

Larson, M.S., (1979), The Rise of Professionalism: A Sociological Analysis, Berkeley: California University Press.

McFarlane, E., (1993), Education 16-19, London: Routledge.

Ozga, J., (1995), 'Deskilling a Profession: Professionalism, Deprofessionalisation and the New Managerialism', in H. Busher and R. Saran, Managing Teachers as Professionals in Schools, London: Kogan Page.

Pollitt, C., (1990), Managerialism and the Public Services, Oxford: Blackwell.

Randle, K. and Brady, N., (1994), 'Further Education and New Managerialism', Journal of Further and Higher Education, 22 (2): 229-39.

Randle, K. and Brady, N., (1997), 'Managerialism and Professionalism in the Cinderella Service', Journal of Vocational Education and Training, 49 (1): 121-39.

Ranson, S., (1994), Toward the Learning Society, London: Cassell.

Ranson, S. and Nixon, J., (1997), 'Theorising Agreement: The Moral Bases of the Emergent Professionalism within the New Management of Education', in Discourse, 18 (2): 197-214.

Seddon, T., (1997), 'Education: Deprofessionalised? Or Reregulated, Reorganised and Re-authorised?', forthcoming in Australian Journal of Education.

Seddon, T. and Brown, L., (1996), 'Teachers' Work and Professionalisation, Towards 2007', unpublished paper, University of Melbourne, Australia.

Watkins, R., (1993), 'Pushing Crisis and Stress Down the Line: The Self-Managing School', in J. Smyth (ed.), A Socially Critical View of the Self-Managing School, London: The Falmer Press.

Watson, T., (1997), "The Labour of Division: Manager as "self" and "other", in $\mathrm{K}$. Hetherington and R. Munro, Ideas of Difference, Oxford: Blackwell. 